\title{
Established Method of High-Speed Railway Survey Control Network
}

\author{
H.Y. Wang , F.Y. Yang and J.F. Gao \\ 1 University of Science and Technology Liaoning College of Civil Engineering, Anshan, China \\ 2 China Railw ay 19th Bureau Group $2^{\text {nd }}$ co.,LTD
}

\begin{abstract}
It is very important of high-speed railway construction surveying and mapping. Especially the establishment of construction survey control network and searching aiming at layout, measurement, data processing of adjustment calculation of the horizontal control network and the elevation control network. The most important part is the establishment of CP II and CPIII control network. The elevation control mainly adopts second order leveling. Horizontal and elevation accuracy must to meet the requirements of high speed railway construction survey.
\end{abstract}

\section{Introduction}

With the progress of technology, high-speed railway has obtained a rapid growth. The new-built speed of $250 \sim 300 \mathrm{~km}$ per hour and the old line of $200 \mathrm{~km}$ per hour are regard as high-speed railway in Western Europe. The international railway agreement which was signed in Geneva in 1985 by the United Nations Economic Commission has stipulated that the speed of new special of passenger train high-speed railway is $300 \mathrm{~km}$ per hour and the speed of new mixed type of passenger and freight trains high-speed railway is $250 \mathrm{~km}$ per hour. In order to achieve the high speed condition for railway trains, the precision of high-speed railway track must be kept in the millimeter range. However, the traditional railway engineering measurement technology cannot meet the require ment of high-speed railway construction. The basis for the high-speed railway precise engineering surveying is setting up horizontal and elevat-ion control network at all levels. Under the control of all levels of precision measurement control network, we can achieve accurate construction and the accuracy of track laying to ensure high speed and safe driving of passenger train. In this paper, the construction technology of high-speed railway construction survey control network is illustrated by a total length of $24.265 \mathrm{~km}$ high-speed railway construction.
WGS-84 coordinate system is adopted in the horizontal coordinate system. According to the principle of grading network, we establish the horizontal control network in four grades. Along the routes, the country's high level horizontal control points are rare and the accuracy is also poor. Therefore, we establish the first GPS framework as the benchmark of horizontal coordinate on the whole line (CP0). The second level is basic horizontal control network (CPI). The third level is line control network (CPII). The four levels is tracking laying and foundation piles control network (CP III ) [1-5].

After the exploration design units surveys CP0、CPI CPII and elevation control network the construction organization carry on making piles and repeating survey. The CP III control points should be measured by construction organization [9-14].

\subsection{Technical requirements of plane control network at all levels}

On the basis of CPII, the construction control network adopts the method of free station intersection. During the construction phase, connecting the CPII and the CP III control network is the main task. CP0、CPI、CPII and CP III network requirements are shown in table 1 , table2 and table3.

\section{Horizontal control network}

Table1. Layout requirements of horizontal control network at all levels

\begin{tabular}{ccccc}
\hline $\begin{array}{c}\text { Levels of Control } \\
\text { Network }\end{array}$ & $\begin{array}{c}\text { Methods of } \\
\text { Measurement }\end{array}$ & $\begin{array}{c}\text { Grades of } \\
\text { Measurement }\end{array}$ & Point Spacing & Remarks \\
\hline CP 0 & GPS & National B -Level & $30 \sim 50 \mathrm{~km}$ & \\
CPI & GPS & B-Level & $\geq 1000 \mathrm{~m}$ & $\leq 4 \mathrm{~km}$ A Pair of Point \\
\hline
\end{tabular}




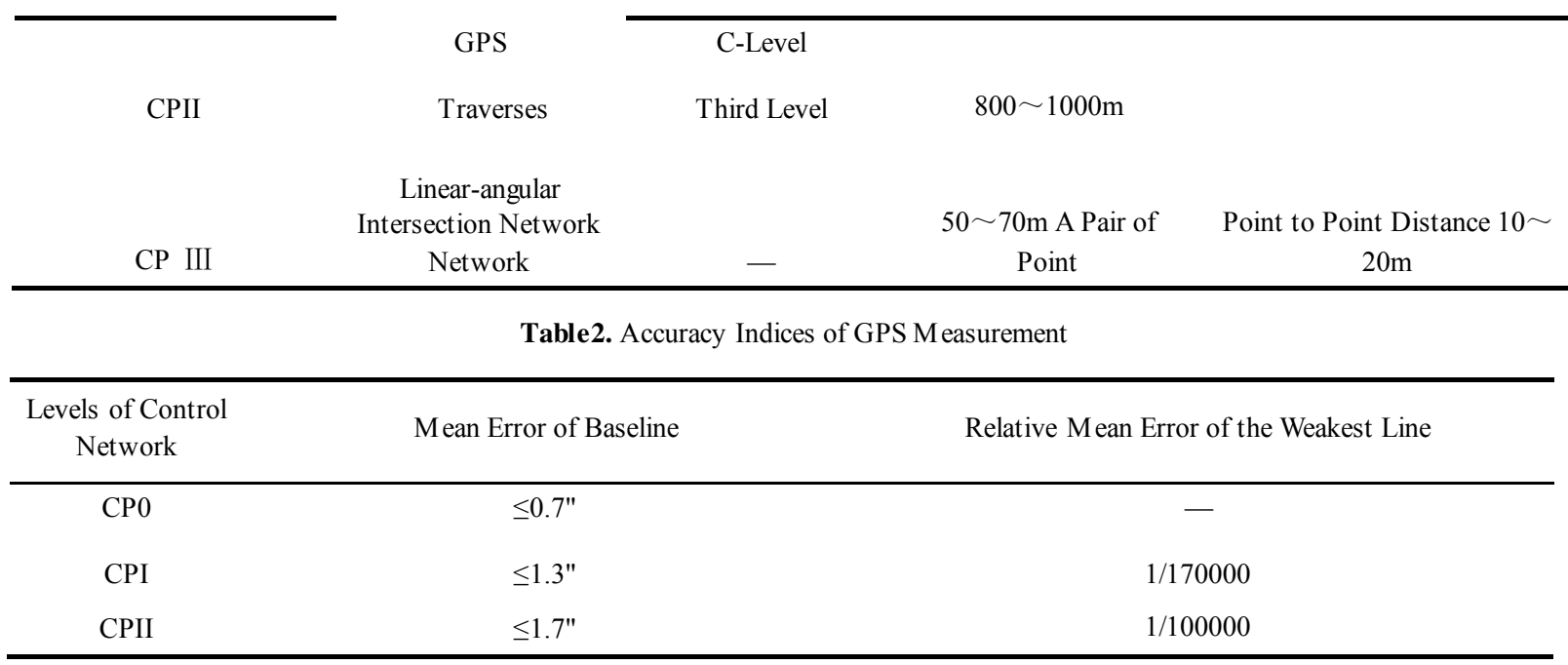

Table3. Technical requirements for traverse survey

\begin{tabular}{|c|c|c|c|c|c|c|c|c|}
\hline Levels of Control & $\begin{array}{c}\text { Echo } \\
\text { Length } \\
(\mathrm{km})\end{array}$ & Length $(\mathrm{m})$ & $\begin{array}{c}\text { Mean } \\
\text { Error of } \\
\text { Distance } \\
\text { M easure } \\
\text { ment } \\
(\mathrm{mm})\end{array}$ & $\begin{array}{l}\text { Mean Error } \\
\text { of Angle } \\
\text { M easureme } \\
\text { nt (") }\end{array}$ & $\begin{array}{l}\text { Mean Error } \\
\text { of Coordinate } \\
\text { in Adjacent } \\
\text { Points }(\mathrm{mm})\end{array}$ & $\begin{array}{c}\text { Relative } \\
\text { Mean Error } \\
\text { of the Total } \\
\text { Length of the } \\
\text { Traverse }\end{array}$ & $\begin{array}{c}\text { Misclosure } \\
\text { Limitation of } \\
\text { Azimuth (") }\end{array}$ & $\begin{array}{c}\text { Corresponding } \\
\text { Traverse } \\
\text { Grades }\end{array}$ \\
\hline CP II & $\leq 5$ & $400 \sim 800$ & 3 & 1.8 & 8 & $1 / 55000$ & $\pm 3.6 \sqrt{n}$ & Third Level \\
\hline
\end{tabular}

\subsection{The horizontal control network shape and the connection measurement methods of CP III}

In order to meet the requirements of CP III measurement, we should carry on a comprehensive repetition measurement and maintenance of basic plane control network CPI, line control network CPII and elevation control network before CP III measurement. Furthermore, we also need to recover the horizontal elevation points which are lost and destroyed.

On the basis of basic plan control network CPI, line control network CPII and elevation control network,
CP III measurement can be laid and measured by construction organization according to the needs of underline engineering and rail construction. As shown in figure $1 \Delta$ is CPI, $\boldsymbol{\Delta}$ is CPII, $\boldsymbol{\otimes}$ is CP III. The number of $1,2,3 \ldots \ldots 14,15 、 16$ in the figure are just the code in this article and not the real CP III point [6-8]. The connecting measurement method: For example, after the instrument set up, centered, and leveled over at station 2, observing CPI 、CPII, using liner-angular intersection we can calculate the coordinate of the station. Then observing CP III again, we can get the coordinate of CP III, too.

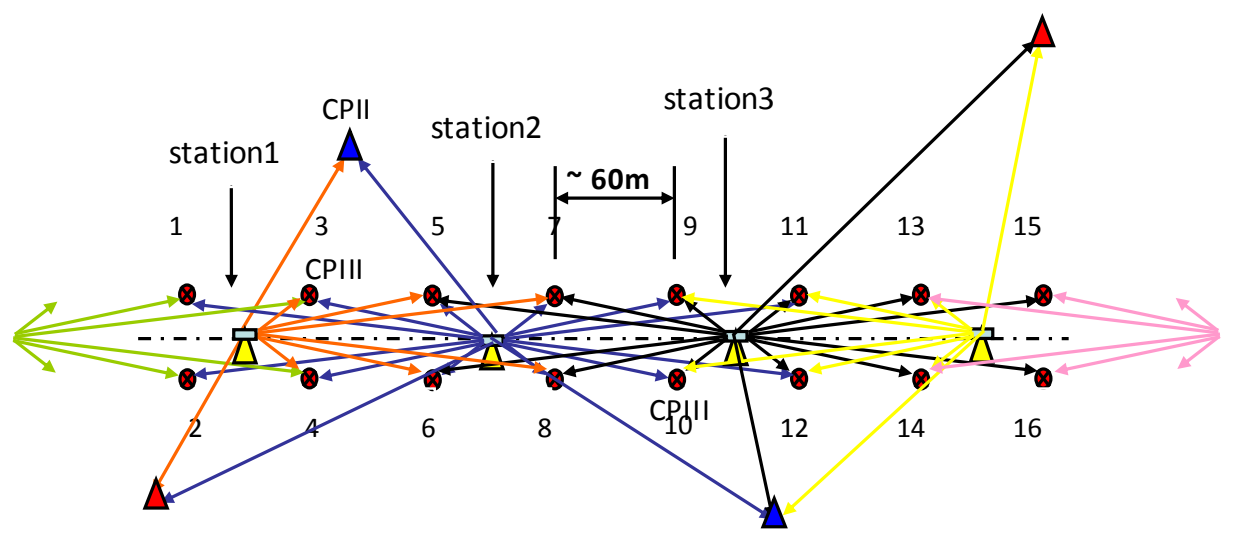

Figure 1. Connecting Measurement Methods of CP III Horizontal Control Network 


\subsection{The observation instrument and limit standard of CP III horizontal network}

\subsubsection{Measuring Instrument}

According to the estimation of the position and the relative position accuracy of the CP III horizontal network, the nominal accuracy of the total station can be used to carry out the standard network observation is mean error of horizontal direction observation in one round $\leqslant \pm 1.0^{\prime \prime}$, mean error of distance measurement $\leqslant \pm(1 \mathrm{~mm}+2 \mathrm{ppm})$, in addition, the total station should have a motor drive, automatic collimation and data recording function. Other accuracy of the total station cannot meet the accuracy requirements of the horizontal network measurement.

\subsubsection{Station Limit}

The method for measuring horizontal direction of CP III plane network is full circle direction observation method which should control the main accuracy indices including the difference value return to zero in semi-observation, the difference between direction value the same direction returning zero and $2 \mathrm{c}$ of the mutual difference value in different value on same direction. Accuracy indices are shown in table 4.

Table 4. The accuracy indices of full circle direction observation

\begin{tabular}{|c|c|c|c|c|c|}
\hline control network name & instrument & set & $\begin{array}{c}\text { the } \\
\text { difference } \\
\text { value return } \\
\text { to zero in } \\
\text { semi-observa } \\
\text { tion }\end{array}$ & $\begin{array}{l}2 \mathrm{c} \text { of the } \\
\text { mutual } \\
\text { difference }\end{array}$ & $\begin{array}{l}\text { the difference } \\
\text { between direction } \\
\text { value the same } \\
\text { direction returning } \\
\text { zero }\end{array}$ \\
\hline \multirow{2}{*}{ CP III } & $0.5^{\prime \prime}$ & 2 & $6^{\prime \prime}$ & $9^{\prime \prime}$ & $6^{\prime \prime}$ \\
\hline & $1^{\prime \prime}$ & 3 & $6^{\prime \prime}$ & $9^{\prime \prime}$ & $6^{\prime \prime}$ \\
\hline
\end{tabular}

\subsection{The adjustment methods of CP III horizontal control network}

Adjustment should not reduce the actual observation accuracy of CP III network, and ensure the smoothness of the track lay ing construction. Adjustment mainly has the following three calculating models: free network adjustment and correction traditional restriction network adjustment and leveling algorithm of CP III .

\section{The elevation control network}

1985 National Elevation datum is adopted in the elevation system.(1)The elevation control network shall be measured according to the required precision of the second-order leveling and the leveling base control network should be measured once on the whole line. When connecting to another railway, to make it easier to determine the relationship between the two railway elevation systems, we always need to carry on connecting measure with bench marks of the other railway. (2)Each bench mark should be set at $2 \mathrm{~km}$. Besides, according to the actual situation the key project area( such as bridges, long tunnels and special roadbed structure) shall be added Bench marks which away from the centre line should be between $50 \sim 150 \mathrm{~m}$ can use a same pile with the plane control points, or be set alone.(3)Leveling method should be adopted in elevation control.

\subsection{Measurement of the elevation control network}

The second-order leveling is adopted in the whole line and the leveling route is laid along the line in principle. Each bench mark should be set at abound $2 \mathrm{~km}$ and each deeply buried bench mark should be set at abound $20 \mathrm{~km}$. According to the actual situation the key project area( such as bridges, long tunnels and special roadbed structure) shall be added. Bench marks which away from the centre line should be between $50 \sim 150 \mathrm{~m}$ need to use a same point with CP II and CP III as far as possible. The location of the bench marks should be safe and quiet. Besides, the places which is on the soli solid, convenient conversation and long term preservation are also take into account. Line bench marks should bury stone by rule and fin ish the description of station. The buried standard of deeply buried bench mark should in accordance with the situation of stratum along the line. The point can be buried to supporting layer or by specially designed according to the actual situation leveling method should be adopted in elevation control and digital level is a good choice. In the process of observation, each section shall be an even number. After leveling operation, every leveling route should calculate accident mean error $\mathrm{M} \Delta$ 
according to the different values of height difference between segments when the number of leveling network rings more than 20 , we should calculate closure error $\mathrm{Mw}$ according the number of rings yet. $\mathrm{M} \Delta$ and $\mathrm{Mw}$ should meet the stipulate, otherwise the routes which have big closure error should be re-measured.

Calculation Formula:

$$
\begin{aligned}
& M_{\Delta}=\sqrt{\frac{1}{4 n}\left[\frac{\Delta \Delta}{L}\right]} \\
& M_{W}=\sqrt{\frac{1}{N}\left[\frac{W W}{L}\right]}
\end{aligned}
$$

In the Formula: $\Delta-$ Difference Values of Height Difference Between Segments (mm);

$\mathrm{L}-$ Measuring Length or Loop Length $(\mathrm{km})$;

$\mathrm{n} \longrightarrow$ the Number of Segments;

W C Closing Error of Rings (mm);

$\mathrm{N} \longrightarrow$ the Number of Rings

\subsection{Establish the foundation piles elevation control network}

The points of the fourth horizontal control network (CPI) are the common points of the horizontal and the elevation control network. Elevation measurement of the CP III control point should be carried out after the completion of the CP III horizontal measurement and in accordance with the requirements of precision leveling measurement, starting and closing at second order basic bench mark. It is suggested that the elevation of the control points should be measured by the digital level and use tightly adjusted.

\subsection{Method of Observation and Adjustment}

1) As shown in figure 2 and figure 3, the observation lines can be seen that whether direct or reversed, all the bench mark of CP III can be linked in the routes.

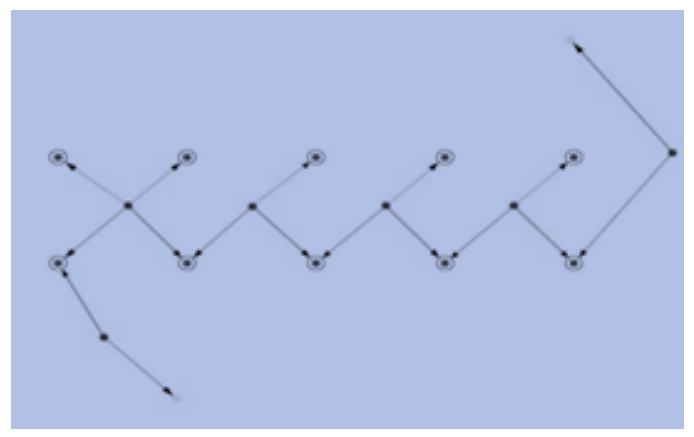

Figure 2. Diagrammatic sketch of the direct leveling route

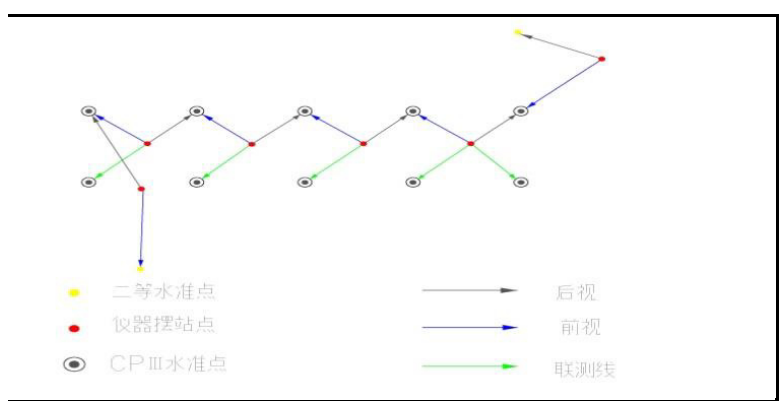

Figure 3. Diagrammatic sketch of the reversed leveling route

2) Each measurement stations are set between the four points and do not have to move the instrument, so as to improve the efficiency of field observation.

3) The length of the horizontal line between the points in the leveling line is also approximately equal. In order to ensure the correctness of CP III leveling measurement,

the method of independent round-trip observation should be adopted to check the level line.

4) The method of indirect adjustment is adopted by the elevation control network adjustment. In addition, restriction adjustment is adopted by connecting to two order leveling point around survey area.

\section{Conclusion}

According to the above control measurement, after the adjustment, the precision index of high-speed railway control measurement is that the correction value of the horizontal distance should be $\leq \pm 3$ "(refer to the station to the CP III point), the mean square error of unit weight of horizontal direction should be $\leq \pm 2.5^{\prime \prime}$, the relative error of the relative position of CP III point should $\leq \pm 1 \mathrm{~mm}$ and the elevation accuracy of the whole station should meet the requirement of the second order leveling.

\section{References}

1. LI Shuliang,,LIU Chenglong, NI Xiantao. Study on the surveying method of CP Ш vertical control network in high-speed railway[J]. Science of Surveying and Mapping, 2011, 36(1): 45-47.

2. Liu Chenglong, Yang Xuefeng, Lu Jiankang, He Bo. Construction and adjustment method for CP Ш trigonometric leveling network of high-speed railway[J]. Journal of southwest jiaotong university, 2011, 46(3): 434-439.

3. Hao Yadong, Li Jufang, Liu Li. High-speed rail ballastless track layout of control network and precision control[J]. Bulletin of Surveying and Mapping, 2011,(8): 51-53. 
4. Zhou Lingyan, Liu Chenglong, Gao Hongtao, Nie Huxiao. Application to a new method of control network inside tunnels in hi-speed railways[J]. Journal of geomatics science and technology, 2014, 31(6): 570-575.

5. Wang Lei, Liu Chenlong, Yang Xuefeng, Chen Haijun. Three-Dimensional adjustment calculation for free station and its precision evaluation in high-speed railway[J]. 2011, 28(4): 258-261.

6. Yan G F, Gao S, Zhang J H, et al. Research on Rigorous Adjustment Lapping between Adjacent of CP III Plane Network[J]. Journal of the China Railway Society, 2014.

7. Ren X C, Zhou D W. Research and Application on the Lapping Methods between Adjacent Sections for CP III Track Control Network for High-speed Railway[J]. Journal of Railway Engineering Society, 2014.

8. Puziewicz J, Matusiak-Ma † F k M, Ntaflos T, et al. Subcontinental lithospheric mantle beneath Central Europe $[\mathrm{J}]$. International Journal of Earth Sciences,
2015, 104(8):1-12.

9. Yang Feng yun Application of GPS Technology for Water Pipeline network in a big city Beijing The Publishing House of Surveying and Mapping 2002.11 P35-36

10. Langley R.B. GLONASS: Review and Update, GPS World, 1997(7), 46-51

11. Zanaoa N. Preliminary Evaluation of the Russian GLONASS System as a Potential Geodetic Tool, Journal of Geodesy, 1998(72), 356-363

12. Gourevitch, S., 1994. Inplications of Z Technology for Civilian Positioning. Proceedings of the ION-GPS-94 Meeting, September 1994, Salt Lake City, Utah, pp. 249-255.

13. Ham,S., 1997.Quality Control Issues Relating to Ambiguity Resolution for Real- Time GPS kinematic Positioning, Journal of Geodesy, 71(6), pp. 351-361.

14. Lorenz et al, US patent Number 5, 134, 407 Magellan Corporation, FGCS Test Report, January 2000 